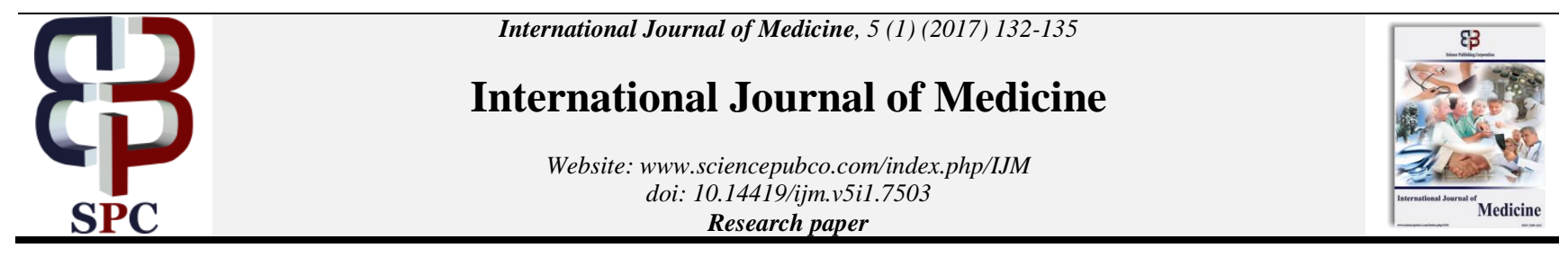

\title{
Medical students utilization of e-learning resources; is it an informal curriculum?
}

\author{
Maria Yaseen *, Misbah Bano, Masood Jawaid \\ Jinnah Sindh Medical University \\ *Corresponding author E-mail: dr.mariaduhs@gmail.com
}

\begin{abstract}
Background: E-learning refers to the use of Internet technologies to deliver a broad range of solutions that enhance knowledge and performance of learners. This mode of learning can be used by institutions to improve the efficiency and effectiveness of educational interventions in the face of the social, scientific, and pedagogical challenges. Worldwide, it has gained popularity in the past few decades; however, its use is highly variable among the medical schools of Pakistan. Currently, a very few number of institutions have adopted it officially in their curriculum. Despite this, many students use different E Learning resources to enhance their learning.

Objective: To find out about the online resources utilized by the medical students in addition to their traditional medical curriculum to enhance their learning.

Method: In this cross-sectional study, 300 participants from Dow Medical College and Jinnah Sindh Medical Universities were included after taking informed consent. A self-administered questionnaire which consists of demographic information, years of study and online resources with their usage details by the students for different subjects of basic and clinical sciences were documented.

Results: Almost all the students reported to use some form of eLearning to enhance their medical understanding. The most frequently used electronic resources were Google images (61.7\%) and Wikipedia (50.3\%). Mostly, the students used YouTube (25.7\%) for animations; Kaplan (27\%) and Dr. Najeeb (15.6\%) for video lectures. However, Audio lecture by Goljan (17.7\%) was the only resource for podcast learning. Among discussion forums, Facebook groups (16.3\%) were most popular and among static websites, Medscape (4.3\%), PubMed (2.5\%), WebMD (1.3\%) were the most commonly used ones.

Conclusion: All of the medical students used some form of eLearning in medical education in addition to their formal curriculum. This way of learning should be further implemented in the form of formal curriculum as e-learning modules for basic and clinical sciences to make learning easier, engaging and innovative for the 21 st century learners.
\end{abstract}

Keywords: Electronic Learning; Medical Education; Online Recourses.

\section{Introduction}

The delivery of a learning, training or education program by electronic means is included in E learning. E learning involves the use with a computer or any other electronic device in some way to provide training, educational or learning material (Derek Stockley 2003). E learning has a well-established role in medical education, and it has been found to have a great influence on increasing the effectiveness of learning (WerneckeE \& PearsonS 2011). It is a new asset in this modern era, and it's getting popular day by day among medical students, because of the increasing availability of portable computer devices (Maxwell Simon \& John Mucklow 2012). A study published by Aggarwal et al. 2015 stated that $78.5 \%$ of the medical students use internet daily and majority access the internet through their phones. Medical students rated internet as the most informative resource as $23 \%$ prefer it over printed books and journals (Aggarwal SS et al. 2015).

Globally, many studies have been conducted to assess the significance and usage of electronic learning in different settings of medical education. In a Danish study, Droup et al. 2004 reported that $46 \%$ of the first year male students were in favor of replacing traditional teaching with electronic learning (Droup et al. 2004). Electronic mediated learning has the potential to provide the learner with an educational environment wherever and whenever desired (Broadbent, B. 2002). Educationalists are emphasizing to assess the influence of E learning in a medical setting and develop an evidence-based system that can inform and shape the future developments (Timmis S \& Cook J 2002).

Furthermore, valuable data is available regarding general usage of electronic learning or web based learning globally but unfortunately, specific electronic resources have not yet been analyzed among undergraduate medical students in our setting. The purpose of this study was to assess and document different electronic modalities that students are using to enhance their learning in theoretical medical and clinical education. This study will help in future to construct an electronic learning module in medical education and to take effective measures in order to enhance and improve elearning in medical education.

\section{Methodology}

This cross sectional study was carried out in January 2013 at Jinnah Sindh Medical University (former Sindh Medical College) and Dow Medical College. The undergraduate medical program follows a five-year integrated curriculum modular system; M.B.B.S (Bachelor of medicine and bachelor of surgery). All the students from 1st year to final year were encouraged to participate and were included after a written consent and a brief note on the 
purpose of the study. Students were asked to fill a specially designed questionnaire that consisted questions on demographic information, year of study, name of institute and E-resources used by students for different subjects of basic and clinical sciences. Students not present on campuses at the time of data collection and those who refused to fill the questionnaire were excluded from this study.

The data was analyzed using SPSS version 16. Frequency and percentage were calculated for all categorical variables. The statistical test used for analyses was chi square for multiple group comparisons. $\mathrm{P}$ value less than 0.005 was considered statistically significant in this study.

\section{Results}

Out of total 300 participants, $n=46$ students were in their first year, $\mathrm{n}=69$ students in their 2 nd year, $\mathrm{n}=59$ students in their third year, $n=62$ students in their fourth year and $n=64$ students in the final year of their M.B.B.S program. According to our study, all the participants $(n=300)$, irrespective of the year of M.B.B.S program, use some form of electronic learning for their medical studies, i.e. $100 \%$.

The different $\mathrm{E}$ learning methods and their specific resources, used by the students is summarized in Table: 1 . According to this Table: 1 , the most frequent electronic resources used by the students were Google images $(61.7 \%)$ and Wikipedia encyclopedia $(50.3 \%)$

The comparison of different $\mathrm{E}$ learning methods, between preclinical and clinical students is outlined in Table: 2. According to this table, audio lectures and websites are more commonly used by clinical students with a significant p-value of 0.001 and p-value 0.005 respectively.

Table 1: Different E Learning Modalities and Resources, Used by Undergraduate Students

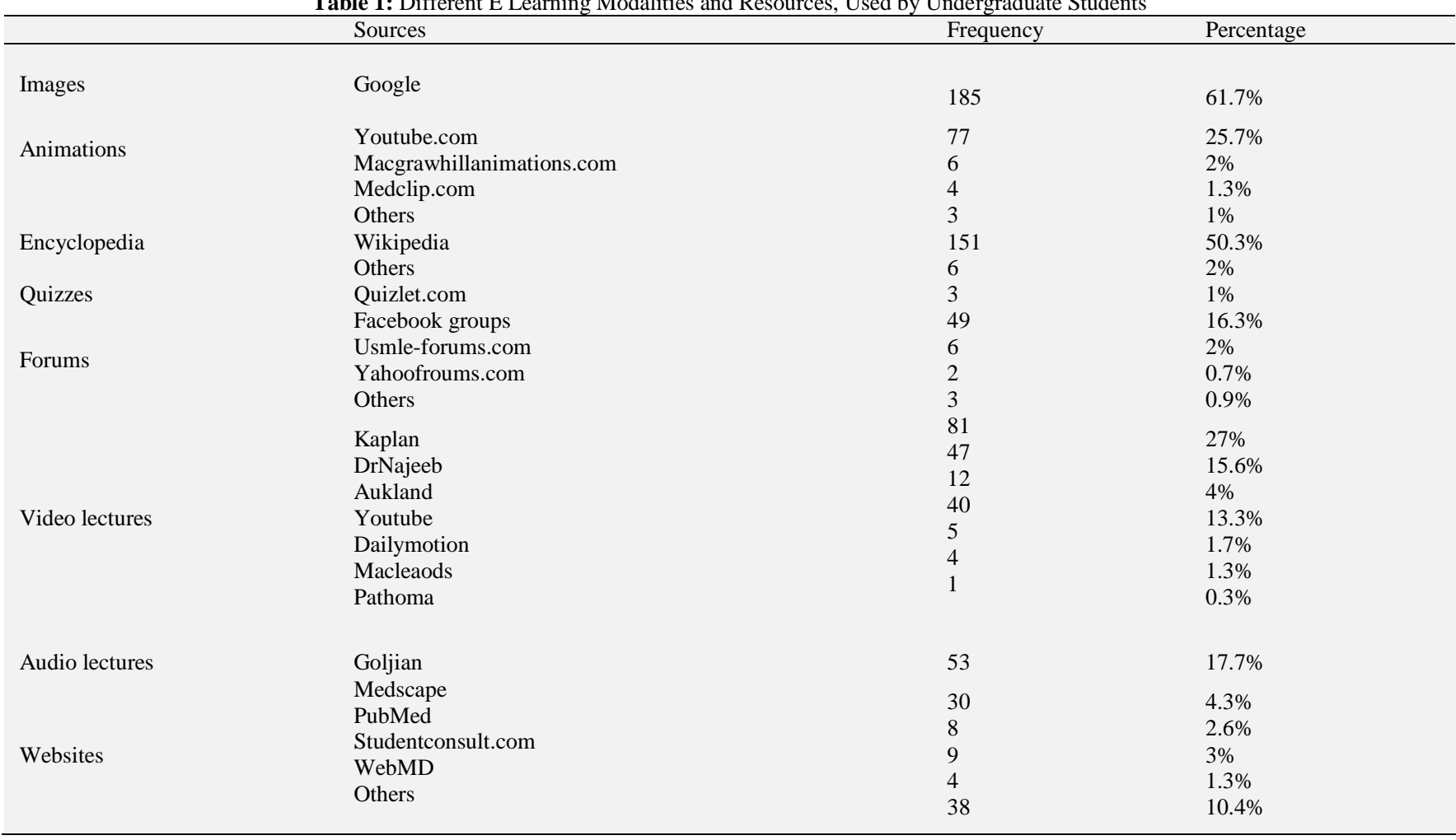

Table 2: Comparison of E-Learning Methods between Pre-Clinical and Clinical Students

Pre-clinical

Clinical

Total

Images

$69(37.3 \%)$

$116(62.75)$

Animations

Quizzes

Forums 
Video Lectures

\section{Discussion}

Our study results showed that almost all the students i.e.100\% used different mode of e-learning to understand and enhance their learning in medical studies whether it is basic sciences or clinical learning. This is quite fascinating and promising.

According to our results, most favorite resources among all students were google images $(67.17 \%)$ and Wikipedia encyclopedia $(50.3 \%)$. For Animations, most of the students rely on YouTube. For video lectures, Kaplan and Dr Najeeb appeared famous in the answers we received. And for the audio lectures, Goljan audio lectures were the only resource documented. As far as the forums are concerned, Facebook groups were most popular while among websites, Medscape, PubMed, WebMD dominated the segment.

In our study, mostly students reported to use google as a primary resource for medical images. This finding can be further emphasized by previous studies with the same results. For instance, a study conducted by Sharam Sedge et al. concluded that the health care professionals prefer google as a primary resource for medical images despite many advances in web-based medical images (Shahram Sedghi et al. 2011) Another study published by D Leo $\mathrm{G}$ et al. 2006 found out that $61 \%$ of the students use google for medical information retrieval whereas PubMed and WebMD were used only by $4.3 \%$ and $2.6 \%$ respectively (De Leo G et al.2006). Results of our study are also similar with google being highest at $67.1 \%$, PubMed at $2.3 \%$ and WebMD at $1.3 \%$.

Wikipedia is a collaboratively written Web-based encyclopedia and has become the dominant online reference work. Globally, Wikipedia is the most-used online website in the health care sector and among medical students apart from Google. When medical information is sought, Wikipedia is among the top search engines (Heilman JM et.al. 2011). In our study, Wikipedia was also the famous encyclopedia among all the students as $50.3 \%$ used it for medical information and understanding.

You tube is one of the most popular resources and contains a large amount of medical educational material.( Azer \& Samy A 2012, Camm et al. 2013) There are many institutions utilizing YouTube as online medical information resource like Mayo clinic YouTube channel contains 4280 videos with 19.5 million views since 2006 . On the other hand, FDA has introduced a multimedia campaign in 2014 to discourage teen smoking. Harvard Medical School has its own channel for surgical techniques and procedure. Mercy medical Center uses YouTube for patient education and posts promotional videos of doctor and services ("More viewers engaging in quality medical care"; available at http://blog.nucleushealth.com/2016/04/18/more-viewersengaging-with-quality-medical-content-on-youtube/, accessed on 23 March 2017). This incredible online technology has revolutionized the way of information retrieval to make it accessible to public which was difficult in previous years. In our study, most of the students also used YouTube for animations and videos, i.e. 25.7\% and $13.3 \%$ respectively. Other resources frequently used by the students for animations were McGraw-Hill animations (2\%) and Med Clip (1.3\%). In our setting, YouTube channels can also be used to help students in terms of better learning and understanding of the medical education.

For audio lectures, most of the students use Goljan audio lectures. These results can be supported with a study published by Micheal Anyryka et al. 2014 in which medical students reported that with regards to the preparation for usmle step 1 (board exam of basic sciences for U.S medical students), goljan audio lectures provide them with excellent explanation of core pathology topics (Micheal Anyryka et al. 2014)

Medical students use Facebook both socially and educationally (El Bialy et al. 2014). According to our findings there has been a significant usage of the Facebook forum (16.3\%) among medical students. Other forums used by students were usmleforum.com and yahooforums.com. Similar results were shared by a study published earlier stating that Facebook help medical students learn professionalism and collaborative learning with peers while also serving as a source of stress management and a source to cultivate interest in research (Brown AD 2010, George DR 2012, AlKhateeb 2014).

Video lectures are again one of the most popular e-learning technologies currently available to medical students. It offers students the reliability to review lectures anytime, anywhere along with the option of pausing if needed. In our study, students reported many different electronic resources like kaplan (27\%), Dr Najeeb $(15.6 \%)$, aukland $(4 \%)$, daily motion $(1.7 \%)$, macleod $(1.3 \%)$ and pathoma $(0.3 \%)$.

Our study has some limitations regarding data collection as this study was conducted in only two institutions of Karachi Pakistan. Thus, the findings cannot be projected for the overall population. As the study aimed to find out the electronic resources, it can be assumed that many of the students were not able to recall the specific resources on that particular moment. The questionnaire of our study consisted of open-ended questions, in contrast to other studies, which have a standardized questionnaire. And hence, it was difficult to analyze and interpret the data with the same level accuracy. Many students cannot afford the available online resources, which are not free to access. As our study was conducted in two public sector universities only, we can assume some difference when it comes to the capacity of learning among the students.

This study can be implemented in various aspects including a generation of e-learning modules for basic and clinical sciences in the medical curriculum. These types of studies should be conducted in future to introduce new tools for medical students in order to use electronic resources in the best possible way with this vast amount of information on the internet. Creating awareness in students can motivate them to use the electronic information in the most useful way while ensuring a win-win situation is achieved.

\section{Conclusion}

In this new era of technology students are bombarded with information from everywhere, as our study reported that every medical student is utilizing E learning in medical studies one way or other. Reforming medical curriculum is the need of time. Thus, gathering the electronic information in the form of E-learning modules and providing easy access to students will help to prioritize their 
time and energy and better results can be achieved by making medical curriculum easy and more engaging to students.

\section{Acknowledgement}

The authors would like to thank Dr. Shahzadi Nisar Bhutto and Dr. Mariam Asif in helping us to collect the data of this study.

\section{References}

[1] Building successful e-learning strategies. Available at http://www.derekstockley.com.au/articles/elearningimplementation.html, Accessed 23 March2017.

[2] WerneckeE \& PearsonS (2011) Medical students perception of using e-learning to enhance the acquisition of consulting skills. Australasian medical journal, $4 \quad$ (6) 300-307. https://doi.org/10.4066/AMJ.2011.73.

[3] Maxwell Simon \& John Mucklow (2012) E-learning initiation to support prescribing. British Journal of Clinical pharmacology.74 (4) 621-631. https://doi.org/10.1111/j.1365-2125.2012.04300.x

[4] Aggarwal SS, Ambalkar DD, Kale KM, Aswar NR\& Bhatkule PR (2015) Pattern of Internet Use among Medical Students: a Cross Sectional Study.Asian Journal of Science and Technology, 6 (4) 1285-1288.

[5] Dørup, Jens (2004) Experience and attitudes towards information technology among first-year medical students in Denmark: longitudinal questionnaire survey. Journal of medical Internet research $6 \quad$ (1) https://doi.org/10.2196/jmir.6.1.e10.

[6] Broadbent, B. (2002). ABCs of e-learning: Reaping the benefits and avoiding the pitfalls. San Francisco, CA: JosseyBass/Pfeiffer.

[7] Timmis S \& Cook J (2002), "'The Neglected Heart' of Online Learning? Motivating students to work effectively with Online Learning Environments", The Way Forward with VLEs: Lessons Learned, 24 June 2002, University of Bristol.

[8] Shahram Sedghi, Mark Sanderson \& Paul Clough (2011) Medical image resources used by health care professionals. Aslib Proceedings $\quad 63,570 \quad 585$. https://doi.org/10.1108/00012531111187225.

[9] De Leo G, LeRouge C, Ceriani C\& Niederman F (2006) Websites Most Frequently Used by Physician for Gathering Medical Information. AMIA Annual Symposium Proceedings/AMIA symposium.AMIA symposium, 902.

[10] [10] Heilman JM, Kemmann E, Bonert M, Chatterjee A, Ragar B Beards GM, Iberri DJ, Harvey M, Thomas B, Stomp W, Martone MF, Lodge DJ, Vondracek A, de Wolff JF, Liber C, Grover SC, Vickers TJ, Meskó B\& Laurent MR (2011) Wikipedia: A Key Tool for Global Public Health Promotion .Journal of medical Internet research $13(1), \mathrm{e} 14$.

[11] Azer \& Samy A (2012) Can "YouTube" help students in learning surface anatomy? Surgical and radiologic anatomy 34 (5 ), 465-468. https://doi.org/10.1007/s00276-012-0935-x.

[12] Camm, Christian F., Nicholas Sunderland, \& A. John Camm. (2013) A quality assessment of cardiac auscultation material on YouTube. Clinical cardiology $36 \quad$ (2), 77-81. https://doi.org/10.1002/clc.22080.

[13] More viewers engaging in quality medical care. Available at http://blog.nucleushealth.com/2016/04/18/more-viewers-engagingwith-quality-medical-content-on-youtube/. Accessed 23 March 2017.

[14] Andryka M, Wilson-Byrne T, Fitzpatrick S, Veitia M, Orwig R \& Shuler FD (2014) too smart to fail: Guide for the struggling medical student. West Virginia Medical Journal 110 (6), 12-19.

[15] El Bialy, Safaa, Ali Jalali, and A \& A. Jaffar. (2014) Integrating Facebook into basic sciences education: a comparison of a facultyadministered Facebook page and group Austin Journal of Anatomy 1(3), 1015.

[16] Brown AD (2010) Social media: a new frontier in reflective practice. Medical Education 44 (8), 744-745. https://doi.org/10.1111/j.1365-2923.2010.03729.x.

[17] George DR, Dellasega C \& Whitehead M (2012) Facebook stress management group for Year 1 medical students. Medical Education 46 (11), 118-118. https://doi.org/10.1111/medu.12034.

[18] Al-Khateeb, A. A., \& Abdurabu, H. Y. (2014). Using social media to facilitate medical students' interest in research. Medical Education Online, 19, 10.3402/meo.v19.25860. 